\title{
VARIABILIDADE SAZONAL DA CONDUTÂNCIA ESTOMÁTICA EM UM ECOSSISTEMA DE MANGUEZAL AMAZÔNICO E SUAS RELAÇÕES COM VARIÁVEIS METEOROLÓGICAS
}

\author{
HERNANI JOSÉ BRAZÃO RODRIGUES ${ }^{1}$; RAFAEL FERREIRA DA COSTA ${ }^{2}$; JOÃO BATISTA \\ MIRANDA RIBEIRO $^{1}$; JOSÉ DANILO DA COSTA SOUZA FILHO ${ }^{1}$; MARIA DE LOURDES PINHEIRO \\ RUIVO $^{3}$; JOÃO DE ATHAYDES SILVA JÚNIOR ${ }^{1}$.
}

\author{
${ }^{1}$ Universidade Federal do Pará (UFPA), Faculdade de Meteorologia, Belém, Pará \\ ${ }^{2}$ Universidade Federal Rural da Amazônia, Parauapebas, Pará. \\ ${ }^{3}$ Museu Paraense Emílio Goeldi, CCTE, Belém, Pará
}
hernani@ufpa.br,rfcosta@ymail.com,jbmr@ufpa.br, danilofilho@ufpa.br, ruivo@museu-goeldi.br, athaydes@ymail.com

Recebido Agosto 2009 - Aceito Outubro 2010

\begin{abstract}
RESUMO
No presente trabalho foram estudadas as variações da condutância estomática $\left(g_{s}\right)$ para o período chuvoso (março) e seco (agosto) do ano de 2003, e suas relações de dependência com algumas variáveis meteorológicas medidas em um ecossistema de manguezal amazônico. As informações utilizadas foram do projeto ECOBIOMA, parte integrante do Experimento de Grande Escala da Biosfera-Atmosfera da Amazônia (LBA). A $g_{s}$ acompanha a tendência de variação do balanço de radiação, atingindo valores máximos durante o dia e mínimos durante a noite. A condutância apresentou maiores flutuações no período chuvoso, com valor médio de $g_{s}=0,015 \mathrm{~m} \mathrm{~s}^{-1}$, porém com magnitudes inferiores as do período seco. Durante a época seca apresentou um valor médio de $g_{s}=0,027 \mathrm{~m} \mathrm{~s}^{-1}$, com menor amplitude, variando de $0,010<g_{s}<0,042 \mathrm{~m} \mathrm{~s}^{-1}$. As variáveis meteorológicas utilizadas para o estabelecimento de relações de dependência com a variabilidade diária de $g_{s}$ foram déficit de umidade específica $(\Delta q)$, déficit de pressão de vapor $(D P V)$, saldo de radiação $(R n)$ e velocidade do vento $(V v)$. O $D P V$ apresentou as melhores correlações com a $g_{s}$ sendo o $R^{2}=0,99 \mathrm{em}$ ambos os períodos. Apesar de também ser importante nas trocas gasosas entre a vegetação e a atmosfera, a $V v$ apresentou a menor influência na variação média da $g_{s}$, com um $R^{2}=0,44$ para época chuvosa e $R^{2}=0,51$ para o período seco.

Palavras-chave: Condutância estomática, déficit de pressão de vapor, floresta de manguezal, saldo de radiação.
\end{abstract}

\section{ABSTRACT: SEASONALVARIABILITY OF THE STOMATALCONDUCTANCE INAMAZONIAN MANGROVE ECOSYSTEM AND THEIR RELATIONSHIPS WITH METEOROLOGICAL VARIABLES}

This work investigated the variations of stomatal conductance $\left(g_{s}\right)$ in the rainy and dry seasons and its dependence relations with meteorological variables measured in an Amazonian mangrove ecosystem. Data were originated from the ECOBIOMA project, part of the Large Scale Biosphere-Atmosphere Experiment in Amazon (LBA). Stomatal conductance followed the tendency of the radiation balance variation, reaching maximum values during the day and minimum values at night. The conductance showed greater fluctuations in the rainy season, with mean value of $g_{s}=0.015 \mathrm{~m} \mathrm{~s}^{-1}$, however smaller in magnitude than in the dry season. During the dry season, the mean value was $g_{s}=0.027 \mathrm{~m} \mathrm{~s}^{-1}$, with lower range, varying between 0.010 and $0.042 \mathrm{~m} \mathrm{~s}^{-1}$. The meteorological variables used for establishing the dependence relations with the daily variability of stomatal conductance were the following; specific moisture deficit $(\Delta q)$, vapor pressure deficit $(P V D)$, net radiation $(R n)$ and wind velocity $(V v)$. The $P V D$ showed the best correlation with $g_{s}$, with $R^{2}=0.99$ for both periods. In spite of the importance of $V v$ in the gaseous changes between the vegetation and the atmosphere, it presented the smallest influence in the mean variation of the gs, with $R^{2}=0,44$ for the rainy and $R^{2}=0,51$ for the dry period. Keywords: Mangrove forest, vapor pressure deficit, net radiation, stomatal conductance. 


\section{INTRODUÇÃO.}

Dentre as diversas funções das florestas, uma das mais importantes é a de atuar como um sumidouro de carbono da atmosfera, utilizado pela vegetação no processo de fotossíntese (Grace et al., 1996; Malhi et al., 1998; Ferreira da Costa, 2000). A vegetação também contribui na reposição de parte do teor de umidade presente na atmosfera, por meio da transferência da água contida no solo, realizada através das trocas gasosas entre a planta e a atmosfera (Ferreira da Costa et al., 2007). As florestas de manguezal, também são importantes biomas, agindo tanto no seqüestro de carbono atmosférico, como na reciclagem da umidade ambiente.

A atividade estomática é um importante fator fisiológico no controle dos processos vitais da planta, além de ser um indicador das condições hídricas do ambiente. A condutância estomática $\left(g_{s}\right)$ é controlada pela turgidez das células-guarda, que regulam a abertura ou fechamento dos estômatos. Assim, a condutância é proporcional ao diâmetro da abertura estomática, e as variações na abertura dos estômatos são devido às diferenças do potencial de água na folha, que dependem da interação de diversos fatores ambientais. O controle estomático da condutância foliar é um mecanismo importante, através do qual as plantas limitam suas perdas de água, sendo freqüentemente utilizado como indicador de déficit hídrico (Mc Dermit, 1990).

Em diferentes condições de solo, salinidade e nutrição, a capacidade de absorção de água pelas raízes das plantas está associada ao poder dessas raízes de atingir elevadas taxas de respiração. A atividade estomática responde às mudanças das condições climáticas, independentes da região. A breve redução na radiação solar incidente sobre uma árvore, provocada pela simples passagem de nuvem, pode acionar a resposta imediata dos estômatos. Alterações na quantidade de radiação fotossinteticamente ativa (RFA), disponível ou no déficit de pressão de vapor $(D P V)$, também são prontamente sentidas pela vegetação (Ferreira da Costa et al., 2003).

Os estômatos também são sensíveis às variações de luz, a temperatura do ar e da folha, e níveis de concentrações de dióxido de carbono $\left(\mathrm{CO}_{2}\right)$ na atmosfera adjacente. A atividade estomática é determinada pela demanda transpirativa a que as folhas estão potencialmente sujeitas e, portanto, determina a taxa de crescimento da planta (Jarvis e McNaughton, 1986; Radersma e Ridder, 1996).

Segundo Kallarackal e Somen (1997) existe um padrão bastante consistente quanto à variação da condutância estomática durante o dia, ou seja, pela manhã, geralmente são observados maiores valores de condutância estomática, enquanto que pela parte da tarde, esses valores são reduzidos. Nesse estudo os autores verificaram que a condutância estomática foi controlada pelo saldo de radiação $(R n)$ e pelo déficit de pressão de vapor $(D P V)$. Assim, a redução da abertura estomática pode ser entendida como uma estratégia evolutiva das plantas para maximizar a eficiência do uso da água, pois os estômatos permanecem com maior abertura apenas quando o déficit de pressão de vapor é menor.

Taconet et al. (1995) estudaram a variação sazonal da evaporação e condutância estomática utilizando dados de sensoriamento remoto sobre uma plantação de soja, e também encontraram que as variações sazonais na condutância estomática estão relacionadas com fatores ambientais, que controlam a abertura estomática, como o potencial de água na folha $\left(\Psi_{f}\right)$ e o déficit de pressão de vapor $(D P V)$.

As variações sazonais da taxa de fotossíntese $(A)$ e da condutância estomática $\left(g_{s}\right)$ em espécies arbóreas, nas regiões tropicais, estão relacionadas às condições de déficit de pressão de vapor $(D P V)$, da temperatura do ar $\left(T_{a r}\right)$ e principalmente da umidade do solo $\left(u_{s}\right)$ características do local e de cada estação climática do ano (Eamus e Cole, 1997; Prior et al., 1997).

Souza Filho et al. (2005) estimaram alguns mecanismos de controle da evapotranspiração no Leste da Amazônia através da aplicação de equações, além de fatores de desacoplamento da transpiração do dossel com a atmosfera.

A capacidade de controle da transpiração de um vegetal é fortemente influenciada pela adaptação da planta ao seu meio ambiente. Em determinadas condições, a abertura ou fechamento dos estômatos que regulam as trocas gasosas entre a planta e a atmosfera são dirigidos pelo conteúdo de água no solo disponível ao sistema radicular. Estas respostas estomáticas são bastante variáveis entre as diversas espécies, que têm inúmeras estratégias de sobrevivência. Mesmo entre indivíduos de uma mesma espécie, há respostas diferenciadas devido à localização dos galhos nas árvores, das folhas nos galhos, e dos estômatos nas folhas. Isto porque, os estômatos sofrem influência direta das condições climáticas (Larcher, 2000). O presente trabalho objetivou analisar as variações na condutância estomática $\left(g_{s}\right)$ para duas épocas distintas (período chuvoso e seco) do ano de 2003 em um ecossistema de manguezal na Amazônia oriental, e as relações de dependência existentes com algumas variáveis meteorológicas.

\section{DADOS E METODOLOGIA}

\subsection{Descrição do sítio experimental}

Este estudo foi desenvolvido no município de Bragança, região litorânea nordeste do Estado do Pará que possui uma área de $3.258 \mathrm{~km}^{2}$. O município limita-se ao norte com o Oceano Atlântico, a leste com os municípios de Augusto Corrêa e Viseu, ao sul com o município de Ourém e a oeste com os municípios de Tracuateua e Capanema. O sítio experimental 
do projeto ECOBIOMA/LBA foi localizado no interior de uma floresta de manguezal ( $01^{\circ} 03^{\prime} \mathrm{S}$; $46^{\circ} 45^{\prime} \mathrm{W}$; $\left.29 \mathrm{~m}\right)$, que fica aproximadamente a $150 \mathrm{~km}$ de distância da desembocadura sul do rio Amazonas e estende-se por uma faixa estimada de até $20 \mathrm{~km}$ de largura.

As espécies dominantes neste ecossistema são a Rhizophora mangle (mangue vermelho), a Avicennia germinans (mangue preto) e a Lagunculária racemosa (mangue branco). O manguezal bragantino é do tipo exuberante, com árvores lenhosas e arbustos densos e altos, apresentando um dossel médio com $20 \mathrm{~m}$ de altura e árvores emergentes de até $25 \mathrm{~m}$ (Ferreira da Costa et al., 2003).

Os dados utilizados nesse estudo são referentes aos meses de março e agosto de 2003, representativos dos períodos chuvosos e secos, respectivamente. As variáveis meteorológicas foram medidas por uma estação meteorológica automática, instalada no topo de uma torre micrometeorológica confeccionada em alumínio, possuindo $25 \mathrm{~m}$ de altura, cujos sensores estão instalados em uma haste $2 \mathrm{~m}$ acima da torre. Para as informações de velocidade do vento $(V v)$ foi utilizado o sensor WIND SENTRY 03001-5 (R. M. YOUNG). O saldo de radiação $(R n)$ foi obtido através do sensor Q7.1 (faixa espectral de 0,25 a $60 \mu \mathrm{m})$. A precipitação pluvial foi obtida através de um pluviógrafo de báscula, TB4-L, com uma resolução de 0,254 mm (Silva Jr. et al., 2006).

Também foi utilizado um sistema de correlação dos vórtices turbulentos (Edisol, Edinburgh, $U K$ ) para a obtenção dos fluxos de energia, calor sensível $(H)$ e calor latente $(L E)$ em alta frequência $(20 \mathrm{~Hz})$, através de um anemômetro sônico tri-dimensional (Solent R-3, Gill instruments, Lymington, $U K)$ e um analisador infravermelho de gás (LI-COR 6262, Lincoln, Nebraska, USA) (Moncrieff et al., 1997), conectados a um computador portátil, que processa as informações em um programa específico (Edire) e armazena os resultados a intervalos de 30 minutos para posterior análise. Todo o sistema foi suprido pela energia gerada por painéis solares e armazenada em um conjunto integrado de baterias.

\subsection{A condutância estomática $\left(g_{s}\right)$}

O controle exercido pelos estômatos sobre o fluxo de água no caminho entre o mesófilo da folha e a atmosfera é representado pela condutância estomática $\left(g_{s}\right)$, obtida pela equação proposta por Penman-Monteith (1948), invertida por (Shuttleworth, 1988):

$$
g_{s}=\left(r_{s}\right)^{-1}=\left\{\frac{\rho_{a} c_{p} D P V}{\gamma L E}-r_{a}\left(1-\frac{\delta H}{\gamma L E}\right)\right\}^{-1}
$$

onde: $g_{s}$ é a condutância estomática $\left(m \cdot s^{-1}\right)$; LE é o fluxo de calor latente $\left(J \cdot \mathrm{m}^{-2} \cdot \mathrm{s}^{-1}\right) ; \rho_{a}$ é a massa específica do ar $\left(\mathrm{kg}^{\mathrm{m}} \mathrm{m}^{-3}\right)$; $c_{p}$ é o calor específico do ar úmido à pressão constante $\left(\mathrm{J} \mathrm{kg}^{-1}\right.$ $\left.{ }^{\circ} C^{-1}\right) ; D P V$ é o déficit de pressão de vapor $(k P a)$; $\gamma$ é a constante psicrométrica $\left(\mathrm{kPa} .{ }^{\circ} \mathrm{C}^{-1}\right) ; r_{a}$ é a resistência aerodinâmica $\left(s . m^{-1}\right)$; $H$ é o fluxo de calor sensível $\left(J \cdot m^{-2} \cdot s^{-1}\right) ; \delta$ é a declividade da curva de pressão de saturação $\left(k P a .{ }^{\circ} \mathrm{C}^{-1}\right)$.

\subsection{0 déficit de pressão de vapor $(D P V)$}

O déficit de pressão de vapor é obtido pela diferença algébrica $\left(e_{s}-e_{a}\right)$, que representa maior ou menor concentração de vapor d'água, ou seja, a pressão que o vapor d'água exerce dentro de um sistema em estudo, assim:

$$
D P V=e_{s}-e_{a}
$$

$e_{a}$ é a pressão parcial do vapor d'água $(h P a)$, determinada pela equação:

$$
e_{a}=\frac{U R \times e_{s}}{100}
$$

$U R$ é a Umidade Relativa do ar (\%) e $e_{s}$ a pressão de saturação do vapor d'água $(h P a)$. A umidade relativa é obtida a partir de dados de temperatura de bulbo seco e bulbo úmido e a pressão de saturação do vapor d'água calculada a partir da temperatura do $\operatorname{ar}(t)\left({ }^{\circ} C\right)$, usando a equação de Tetens a seguir:

$$
e_{s}=6,1078 \times 10^{\left[\frac{7,5 \times t}{237,3+t}\right]}
$$

\section{$2.4 O$ déficit de umidade específica $(\Delta q)$}

Considerando-se que as massas dos constituintes atmosféricos são proporcionais às suas pressões, então a umidade específica pode também ser determinada, utilizando-se a equação da termodinâmica para gases ideais, e realizando simplificações matemáticas, pode-se expressar a umidade específica em gramas de vapor d'água por quilograma de ar:

$$
q=\frac{622 e_{a}}{P-0,378 e_{a}}
$$

onde $P$ é a pressão atmosférica local em $(h P a)$.

A umidade específica de saturação $\left(q_{s}\right)$ é obtida substituindo $e_{a}$ pela pressão de vapor de saturação $\left(e_{s}\right)$ na Equação 5. O déficit de umidade específica $(\Delta q)$ é obtido pela diferença algébrica $\left(q_{s}-q\right)$, que representa a disponibilidade ou carência de vapor d'água dentro do sistema em estudo, assim:

$$
\Delta q=q_{s}-q
$$


saldo de radiação $(R n)$ e velocidade do vento $(V v)$ foram medidas no campo.

Para as análises das variações da condutância estomática $\left(g_{s}\right)$, foram excluídos os horários em que ocorreram eventos de precipitação pluvial, e até três horas após estas ocorrências. Este foi o tempo máximo estimado para que toda água interceptada no dossel evaporasse. Devido a este critério de seleção dos dados, o mês de março de 2003, por estar inserido no período chuvoso da região, apresenta uma menor quantidade de informações utilizadas neste estudo, porém sem perda na qualidade das análises.

\section{RESULTADOS}

Como foram selecionados dois períodos com características de precipitação pluvial (Figura 1a) bastante distintos, durante o ano de 2003, enfatizaram-se as diferenças sazonais encontradas nas variáveis analisadas neste estudo. Para o período chuvoso (março), foram observados aumentos acentuados nas condutâncias estomáticas $\left(g_{s}\right)$, nas primeiras horas da manhã, atingindo valores máximos entre 08 e 09 h, enquanto que no período seco (agosto), os máximos foram entre 11 e 12 h. Nos dois períodos, a partir deste horário, as condutâncias decresceram até o final da tarde, indicando um maior fechamento estomático. $\mathrm{O}$ padrão diário observado da condutância estomática $\left(g_{s}\right)$, para o manguezal de Bragança, é similar ao encontrado em diferentes estudos conduzidos na Amazônia em florestas de terra firme (Roberts et al., 1996; Williams et al., 1996; Taconet et al., 1995; Carswell et al., 2002; Souza Filho et al., 2005).

As variações diárias da condutância estomática $\left(g_{s}\right)$, relacionadas com o déficit de umidade específica $(\Delta q)$ para as épocas chuvosa e seca são apresentadas nas Figuras $1 \mathrm{~b}$-c, respectivamente. A interdependência entre as variáveis é bem estabelecida, uma vez que os maiores valores do déficit de umidade específica (que indicam menor concentração de umidade no ar) foram observados no período seco, com $\Delta q>$ $7 \mathrm{~g} \mathrm{~kg}^{-1}$ em todos os dias monitorados, com ocorrências de $\Delta q$ $>8 \mathrm{~g} \mathrm{~kg}^{-1}$ em alguns dias. Para este mesmo período, também foram observados maiores valores de condutância estomática, que em vários dias registraram valores de $g_{s}>0,035 \mathrm{~m} \mathrm{~s}^{-1}$, com picos de $g_{s}>0,040 \mathrm{~m} \mathrm{~s}^{-1}$. Souza Filho et al., (2005), estudando uma região de floresta tropical úmida, encontraram valores máximos de $g_{s}=0,045 \mathrm{~m} \mathrm{~s}^{-1}$ durante a estação seca. Apesar de neste período serem registrados os maiores valores tanto de $\Delta q$ como de $g_{s}$, houve uma menor amplitude nas medidas de $g_{s}$ que oscilou entre $0,01<g_{s}<0,04 \mathrm{~m} \mathrm{~s}^{-1}$, e $\Delta q$ variou de $3<$ $\Delta q<9 \mathrm{~g} \mathrm{~kg}^{-1}$.

Para o mês de março de 2003 (chuvoso) a vegetação do manguezal bragantino apresentou valores de $\Delta q>8 g$ $\mathrm{kg}^{-1}$ apenas em três dias monitorados, quando também foram observados valores de $g_{s}>0,035 \mathrm{~m} \mathrm{~s}^{-1}$. Nesse período houve
1 a)

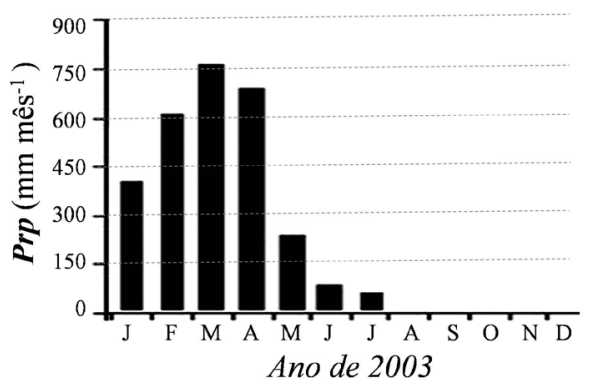

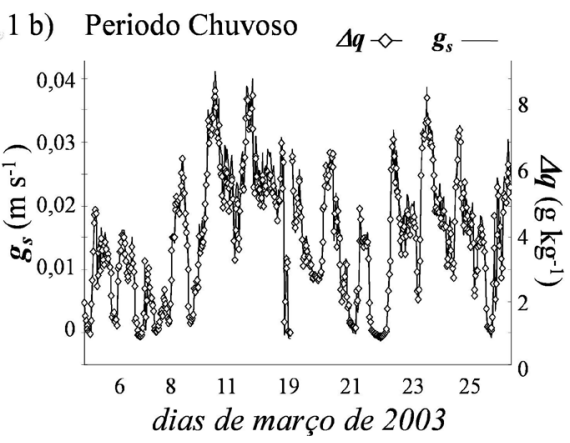

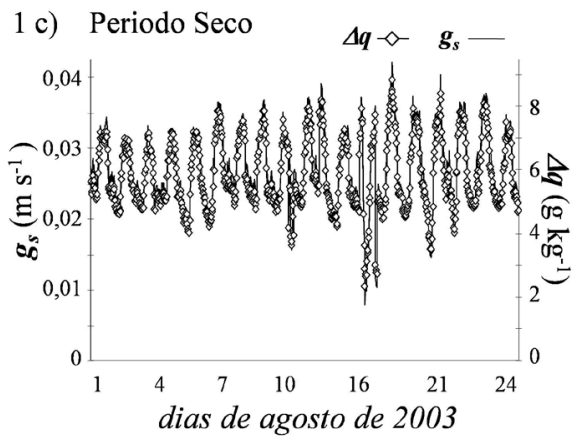

Figura 1 - Precipitação pluvial mensal (Prp) durante o ano de 2003 (1a), variabilidades temporais da condutância estomática $\left(g_{s}\right)$ e do déficit de umidade específica $(\Delta q)$ para os meses de março e agosto de 2003, períodos chuvoso (1b) e seco (1c), respectivamente, no manguezal de Bragança, Pará. 
uma maior variação, tanto de $0<g_{s}<0,04 \mathrm{~m} \mathrm{~s}^{-1}$, como de 1 $<\Delta q<9 \mathrm{~g} \mathrm{~kg}^{-1}$. Para a floresta de terra firme, Souza Filho et al., (2005) encontraram valores máximos de $g_{s}=0,060 \mathrm{~m} \mathrm{~s}^{-1}$ durante a época chuvosa.

Ao diminuir a concentração de umidade na atmosfera, o ar aumenta seu poder evaporativo, o que induz a maiores trocas gasosas entre as plantas e a atmosfera, através dos estômatos. Estas relações são visualizadas nas Figuras $2 \mathrm{a}-\mathrm{b}$, em que as regressões lineares apresentam coeficientes de determinação $R^{2}$ $=0,79$ (período chuvoso) e $R^{2}=0,87$ (período seco).

O déficit de pressão de vapor $(D P V)$ apresentou uma maior variabilidade no período chuvoso (março), quando atingiu picos entre $2<D P V<14 \mathrm{kPa}$ (Figura $3 \mathrm{a}$ ), visto que nos períodos de chuvas é normal a atmosfera estar freqüentemente com grande teor de umidade, reduzindo sobremaneira o $D P V$. Fato este que já não ocorre com tanta freqüência no período seco (agosto), quando os déficits de pressão de vapor oscilaram entre $6<D P V<14 \mathrm{kPa}$ (Figura 3b), com raras ocorrências com $D P V<6 \mathrm{kPa}$, visto que a quantidade de umidade contida na atmosfera é mais reduzida, quase que permanentemente, exceto quando da ocorrência dos raros eventos de chuva, fazendo com que o $D P V$ seja elevando nesta época do ano. Em seus estudos

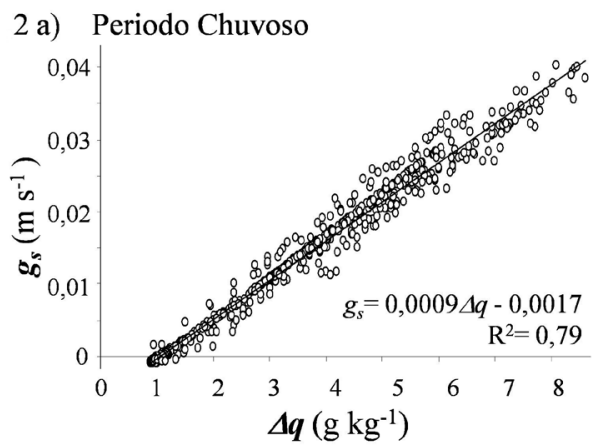

para uma região de floresta tropical de terra firme, Souza Filho et al., (2005) registraram valores médios de $D P V=5,8 \mathrm{kPa}$ para o período chuvoso e de $D P V=10,8 \mathrm{kPa}$ durante a estação seca.

O déficit de pressão de vapor foi a variável que apresentou a melhor relação com a condutância estomática $\left(g_{s}\right)$, independente da época do ano. As correlações lineares apresentaram coeficientes de determinação $R^{2}=0,99$ para ambos os períodos (Figuras 4a-b). Este resultado caracteriza claramente que a condutância estomática varia (aumenta ou diminui) proporcionalmente ao déficit de pressão de vapor. Uma vez que a área de estudo se encontra em um ecossistema de manguezal, que possui solo constantemente encharcado pelo efeito de marés, não há restrição hídrica no solo, sendo a absorção de água e nutrientes pelo sistema radicular limitado por outros fatores, principalmente pela salinidade presente no solo, como foi destacado por Ferreira da Costa et al., (2003). Então, a condutância estomática é influenciada primordialmente pelas condições atmosféricas, ou seja, se há mais vapor d'água na atmosfera diminui o déficit de pressão de vapor, e conseqüentemente, diminui a condutância estomática e vice-versa.

De maneira geral, a vegetação responde aos efeitos do meio ambiente de uma forma heliossíncrona, ou seja, sua

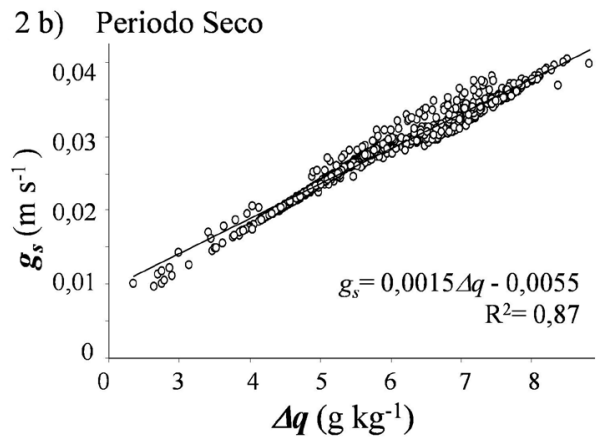

Figura 2 - Correlações lineares da condutância estomática $\left(g_{s}\right)$ com o déficit de umidade específica $(\Delta q)$ para os meses de março e agosto de 2003 , períodos chuvoso (2a) e seco (2b), respectivamente, no manguezal de Bragança, Pará.
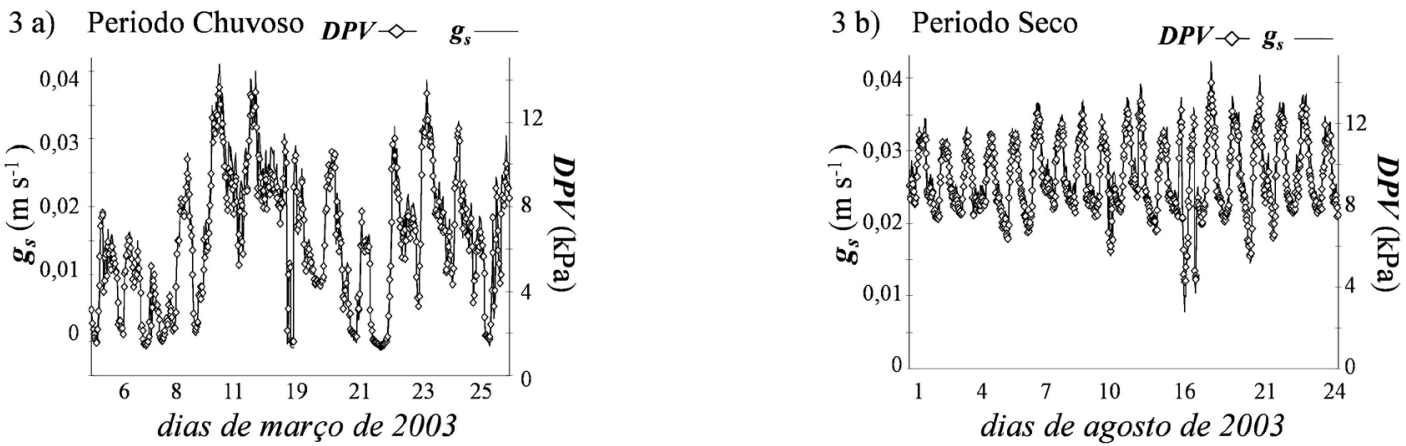

Figura 3 - Variabilidades temporais da condutância estomática $\left(g_{s}\right)$ e do déficit de pressão de vapor $(D P V)$ para os meses de março e agosto de 2003, períodos chuvoso (3a) e seco (3b), respectivamente, no manguezal de Bragança, Pará. 
4 a) Periodo Chuvoso

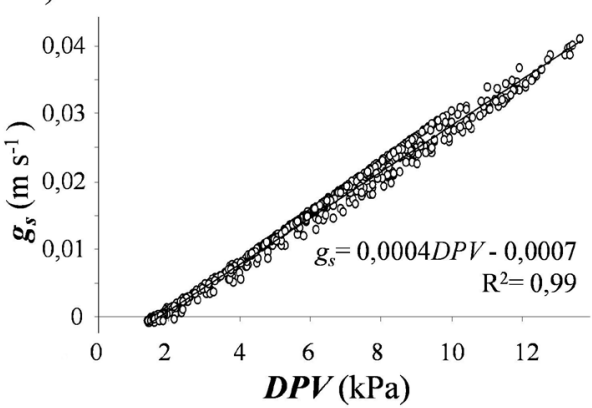

4 b) Periodo Seco

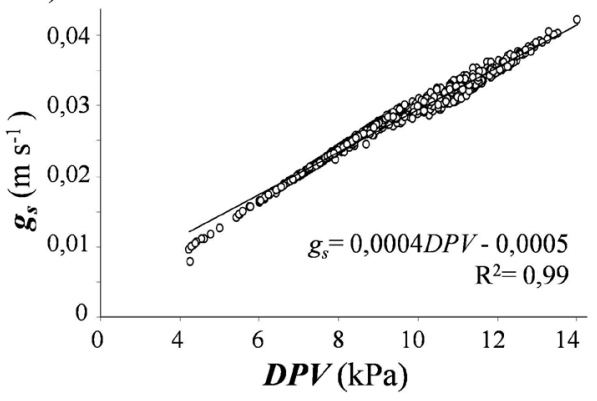

Figura 4 - Correlações lineares da condutância estomática $\left(g_{s}\right)$ com o déficit de pressão de vapor $(D P V)$ para os meses de março e agosto de 2003 , períodos chuvoso (4a) e seco (4b), respectivamente, no manguezal de Bragança, Pará.

Tabela 1 - Equações das regressões lineares das correlações entre a condutância estomática $\left(g_{s}\right)$ e as diferentes variáveis; déficit de umidade específica $(\Delta q)$, déficit de pressão de vapor $(D P V)$, saldo de radiação $(R n)$ e, velocidade do vento $(V v)$, para o período chuvoso (março) e seco (agosto) do ano de 2003, no manguezal de Bragança, Pará.

\begin{tabular}{lllcc}
\hline Variáveis & Períodos & Modelos matemáticos & \multicolumn{2}{c}{ Coeficientes } \\
& & & $\begin{array}{c}\text { Determinação } \\
\left(R^{2}\right)\end{array}$ & $\begin{array}{c}\text { Correlação } \\
(r)\end{array}$ \\
\hline \multirow{2}{*}{$g_{s} \times \Delta q$} & Chuvoso & $g_{s}=0,0009 \Delta q-0,0017$ & 0,79 & 0,888 \\
& Seco & $g_{s}=0,0015 \Delta q-0,0055$ & 0,87 & 0,933 \\
\hline \multirow{2}{*}{ Chuvoso } & $g_{s}=0,0004 D P V-0,0007$ & 0,99 & 0,995 \\
$g_{s} \times D P V$ & Seco & $g_{s}=0,0004 D P V-0,0005$ & 0,99 & 0,995 \\
\hline \multirow{2}{*}{$g_{s} \times R n$} & Chuvoso & $g_{s}=7^{-6} R_{n}+0,0008$ & 0,75 & 0,866 \\
& Seco & $g_{s}=7^{-6} R_{n}+0,0021$ & 0,92 & 0,959 \\
\hline \multirow{2}{*}{$g_{s} \mathrm{X} V v$} & Chuvoso & $g_{s}=0,001 V_{v}-0,0002$ & 0,44 & 0,663 \\
& Seco & $g_{s}=0,0014 V_{v}-0,0014$ & 0,51 & 0,714 \\
\hline
\end{tabular}

atividade estomática sofre uma intensificação concomitante com a disponibilidade radiativa proporcionada pelo Sol. Nas áreas de manguezal, fatores como disponibilidade hídrica, nutricional e salinidade também interferem nas atividades vegetais, porém, apresentam respostas mais demoradas, caracterizadas pelo ponto de murcha temporária ou a redução na taxa de crescimento da planta. Já uma reposta à luz solar, tende a ser quase que imediata.

Foram calculadas as correlações lineares entre a condutância estomática e o saldo de radiação para o período chuvoso e seco no manguezal. Observou-se que essas variáveis têm uma relação de dependência maior no período seco $\left(R^{2}=\right.$ $0,92)$, do que no período chuvoso $\left(R^{2}=0,75\right)$, provavelmente devido à maior presença de nebulosidade que resulta em ocorrências de precipitações. Estes eventos de chuva modificam temporariamente as condições micrometeorológicas, o que influencia na condutância estomática (Tabela 1).
Também foram analisadas as relações da velocidade do vento $(V v)$ com condutância estomática $\left(g_{s}\right)$, visto que, o vento tem papel importante nas trocas de energia entre as plantas e o meio ambiente. $\mathrm{O}$ vento renova continuamente a camada de ar em contato com a superfície das folhas, reduzindo a resistência aerodinâmica, o que facilita as trocas de vapor d'água entre o mesófilo da folha e o ar adjacente.

$\mathrm{O}$ vento é originado por aquecimento diferencial de superfícies, gerando um gradiente térmico que provoca variações de pressão, e conseqüentemente, o deslocamento de massa de ar. O curso diário da velocidade do vento acompanha as variações do balanço de radiação; dessa forma, a velocidade do vento tende a ser maior durante o dia, quando o continente se aquece mais rapidamente que o oceano, provocando a brisa marítima. Durante o período noturno a situação se inverte, com a ocorrência da brisa terrestre, que é resultado de um maior aquecimento no oceano em relação ao continente. A maior 
velocidade do vento é verificada durante a estação seca, devido às maiores temperaturas que resultam em maiores gradientes de pressão. Em termos médios sazonais, no manguezal bragantino registra-se para a época chuvosa, $V v=1,9 \mathrm{~m} \mathrm{~s}^{-1}$, enquanto que para o período seco, $V v=3,4 \mathrm{~m} \mathrm{~s}^{-1}$ (Silva Júnior et al., 2006). Contudo, apesar da participação do vento nos processos de trocas gasosas entre a vegetação e a atmosfera, sua relação de dependência com a condutância estomática é secundária, apresentando coeficientes de determinação de 0,44 para época chuvosa e 0,51 para época seca (Tabela 1). Todavia, vale ressaltar que a correlação mais alta dá-se no período seco, quando ocorrem ventos mais fortes. De uma forma geral, fica caracterizado que o vento não representa uma variável determinante sobre a condutância estomática e sim um contribuinte que facilita os processos de trocas energéticas entre a vegetação e a atmosfera.

\section{CONCLUSÕES}

As variações sazonais da condutância estomática $\left(g_{s}\right)$ no manguezal bragantino foram semelhantes às verificadas em regiões de floresta também na Amazônia. Os maiores valores de condutância estomática, em média, foram obtidos no período seco e as maiores amplitudes foram observadas no período chuvoso.

A condutância estomática foi fortemente controlada pelo déficit de pressão de vapor $(D P V)$. As correlações entre estas variáveis foram sempre consideráveis, tanto no período chuvoso como no período seco do ano de 2003.

O saldo de radiação $(R n)$ foi claramente mais importante no controle estomático durante o período seco quando comparado à época chuvosa.

A velocidade do vento $(V v)$ apresentou as menores correlações com a condutância estomática nas duas épocas analisadas. Sendo assim, pode ser considerada de importância secundária no controle estomático.

\section{AGRADECIMENTOS}

Os autores agradecem ao projeto LBA/ECOBIOMA, a todos os colegas que participaram da instalação e coleta de dados no sítio experimental do manguezal de Bragança, Pará, e ao Projeto CNPq/MCT 47.4221/2007-5 e CNPq/FAPESPA 68.0007/2008-3.

\section{REFERÊNCIAS BIBLIOGRÁFICAS}

CARSWELl, F. E.; COSTA, A. C. L.; PALHETA, M.; MALHI, Y.; COSTA, J.P.R.; LEAL, L.S.M.; COSTA, J.M.N.; CLEMENTE, R.J.; GRACE, J. Seasonality in
$\mathrm{CO}_{2}$ and $\mathrm{H}_{2} \mathrm{O}$ flux at an eastern Amazonian rain forest. Journal of Geophysical Research, v.107, n. D20, art. N. 8076, 2002.

EAMUS, D.; COLE, S. Diurnal and seasonal comparisons of assimilation, phyllode conductance and water potential of three Acacia and one Eucalyptus species in the wet-dry tropics of Australia. Australia Journal of Botanic, v.45, p.275-290, 1997.

FERREIRA DA COSTA, R.; Fluxos de dióxido de carbono em uma área de floresta na Amazônia Central. 2000, 97p. Dissertação de Mestrado. Escola Superior de Agricultura Luiz de Queiroz, Universidade de São Paulo, ESALQ/USP. Piracicaba, SP. http://143.107.213.59:4500/ALEPH/POR/ ESA/ESA/TESESA/FIND-ACC/0181125

FERREIRA DA COSTA, R.; MEIR, P.; OLIVEIRA, P.J.; MALHI, Y.; COSTA, A.C.L.; COSTA, J.M.N.; SILVA, R.B.C.; ANDRADE, V.M.S.; BRAGA, A.P.; GONÇALVES, P.H.L. E SILVA JUNIOR, J.A. Transporte de Seiva em Espécies Vegetais de um Ecossistema de Manguezal Bragança, Pará, Brasil. Mangrove 2003 - Articulando pesquisa e gestão participativa de estuários e manguezais. Salvador, Bahia, p.175, 2003.

FERREIRA DA COSTA, R.; SILVA, V.P.R.; RUIVO, M.L.P.; MEIR P.; COSTA, A.C.L.; MALHI, Y; BRAGA, A.P.; GONÇALVES, P.H.L.; SILVA JUNIOR, J.A.; GRACE, J. Transpiração em espécie de grande porte na Floresta Nacional de Caxiuanã, Pará. Revista Brasileira de Engenharia Agrícola e Ambiental, v.11, n.2, p.xxx-ccc, 2007. doi: 10.1590/S1415-43662007000200008

GRACE, J.; LLOYD, J., MCINTIRE, J.; MIRANDA, A., MEIR, P.; MIRANDA, H., Carbon dioxide flux over Amazon rainforest in Rondonia. In: Gash, J.H.C.; Nobre, C.A.; Roberts, J.M.; Victoria, R.L. (Eds.) Amazonian deforestation and climate. Chichester, John Willey \& Sons, p.307-317, 1996.

JARVIS, P. G.; MCNAUGHTON, K. G. Stomatal controlo of transpiration: scaling up from leaf to region. Advances in Ecological Research, v.15, p.1-49, 1986.

KALLARACKAL, J.; ND SOMEN, C. K. An ecophysiological evaluation of the suitability for plant in the tropics. Forest Ecological and Manegement, v.95, p.53-61, 1997.

LARCHER, W. Ecofisiologia Vegetal. RiMa, São Paulo, 531p. 2000.

MALHI, Y.; NOBRE, A.D.; GRACE, J.; KRUIJT, B.; PEREIRA, M.G.P.; CULF, A.D.; STEVE, S. Carbon dioxide transfer over a Central Amazonian rain forest. Journal of Geophysical Research, v.103, n.D24, p.31593-31612, 1998.

MC DERMIT, D.K. Sources of error in the estimation of stomatal conductance and traspiration from porometer data. HortSci. Alexandria, v. 25, n. 12, p. 1538- 1548, 1990. 
MONCRIEFF, J.B.; MASSHEDER, J.M.; DE BRUIN, H.; ELBERS, J.; FRIBORG, T.; HEUSINKVELD, B.; KABAT, P.; SCOTT, S.; SOEGGARD, H.; VERHOEF, A. A system to measure surface fluxes of momentum, sensible heat, water vapour and carbon dioxide, Journal of Hydrology, v.188-189, p.589-611, 1997.

PRIOR L.D.; EAMUS, D.; DUFF, G.A. Seasonal and diurnal patterns of carbon assimilation, stomatal conductance and leaf water potential in Eucalyptus tetrodonta sampling in a wet-dry savanna in northern Australia. Australia Journal of Botanic, v.45, p.241-258, 1997.

RADERSMA, S.; RIDDER, N. Computed evapotranspiration of annual and perennial crops at different temporal and spatial scales using published parameter values. Agricultural Water Management, v.31, p.17-34, 1996.

ROBERTS, J. M.; CABRAL, M. R.; COSTA, J. P.; WILLIAM, A. L. C.; SÁ, T. D. An overview of the leaf area index and physicological measurements during ABRACOS. In: Gash, J.H.C.; Nobre, C.A.; Roberts, J.M.; Victoria, R.L. (Eds.) Amazonian deforestation and climate. Chichester, John Willey \& Sons, 1st ed., 287-306, 1996.

SHUTTLEWORTH, W.J. Corrections for the effects of background concentrations change and sensor drift in real-time eddy correlations systems. Boundary Layer Meteorology, v.42, p.167-180, 1988.
SILVA JUNIOR, J.A.; FERREIRA DA COSTA, R.; COSTA, A.C.L.; GONÇALVES, P.H.L.; BRAGA, A.P.; MALHI, Y; ARAGÃO, L.E.O.C.; COSTA, M.C.; MEIR P. Sazonalidade de elementos meteorológicos em ecossistema de manguezal na região equatorial, Pará, Brasil. Revista Brasileira de Meteorologia, v.21, n.3b, p. 241-247, 2006.

SOUZA FILHO, J.D.C.; RIBEIRO, A.; COSTA, M.H.; COHEN, J.C.P. Mecanismos de controle da variação sazonal da transpiração de uma floresta tropical no nordeste da Amazônia. Acta Amazônica, v.35; n.2; p.223-229; 2005.

TACONET, O.; OLIOSO, A.; MEHREZ, M. B.; BRISSON, N. Seasonal estimation of evaporation and stomatal conductance over a soybean field using surface IR temperatures. Agricultural and Forest Meteorology, v.73, p.321-337, 1995.

WILLIAMS, M.; RASTETTER, E. B.; FERNANDES, D. N.; GOULDEN, M. L. Modelling the soil-plant-atmosphere continuum in a stand at Harvard forest: the regulation of stomatal conductance by light, nitrogen and soil/plant hydraulic properties. Plant Cell Environmental, v.19, p.911-927, 1996. 